\title{
Assessing the Accuracy of Ortho-image using Photogrammetric Unmanned Aerial System
}

\author{
H. H. Jeong ${ }^{\text {a }}$ J. W. Park ${ }^{\text {a }}$ J. S. Kimª ${ }^{\text {a }}$ C. U. Choi ${ }^{\text {a }}$ *
}

a Dept. of Spatial Information Engineering, Pukyong National University, South Korea - skyeyes82@ pukyong.ac.kr

\author{
Commission I, ICWG I/Vb
}

KEY WORDS: UAV, Ortho-image, Photogrammetry, Camera calibration

\begin{abstract}
:
Smart-camera can not only be operated under network environment anytime and any place but also cost less than the existing photogrammetric UAV since it provides high-resolution image, 3D location and attitude data on a real-time basis from a variety of built-in sensors. This study's proposed UAV photogrammetric method, low-cost UAV and smart camera were used. The elements of interior orientation were acquired through camera calibration. The image triangulation was conducted in accordance with presence or absence of consideration of the interior orientation (IO) parameters determined by camera calibration, The Digital Elevation Model (DEM) was constructed using the image data photographed at the target area and the results of the ground control point survey. This study also analyzes the proposed method's application possibility by comparing a Ortho-image the results of the ground control point survey. Considering these study findings, it is suggested that smartphone is very feasible as a payload for UAV system. It is also expected that smartphone may be loaded onto existing UAV playing direct or indirect roles significantly.
\end{abstract}

\section{INTRODUCTION}

In order to perform observation activities in the target area, the Photogrammetric UAV System operates the aircraft remotely or automatically with loading cameras, sensors, communications equipment, or other payload (Dalamagkidis et al., 2008). It can be operated at a low cost compared to traditional aerial photogrammetry, and is possible to real-time applications (Chiabrando et al., 2011). In addition, UAVs can provide a continuous image of the ground that has a proper overlap at low altitude for photogrammetry (Eisenbeiss and Zhang, 2006; Lambers et al., 2007).

As intelligent terminals with the ubiquitous concept, smart devices (smart phone, smart camera and so on) can be operated anytime and anywhere in the communications environment, and embed a variety of MEMS sensors. In particular, the smart camera does not only embed camera that supports highresolution images with the development of the DSLR camera, but also load some sensors of providing the location of the fuselage and detailed information, such as GPS, accelerometer, magnetometer and gyroscope.

In other words, since a very small weight(less than $120 \mathrm{~g}$ ) of smart camera is possible to replace the payloads' function of the existing UAV system, it can be applied well by loading to all types of UAVs without the constraints of the weight on board that have been raised from the existing UAV system. In addition, smart phone includes some functions, such as internet, e-mails, SMS (short messaging service), MMS (multi-media messaging service), and IM (Instant Messaging) (Chang et al, 2009). Therefore, the flying UAV in the field and the data provided from the photogrammetric UAV system can be monitored in real time using a smartphone. Furthermore, anyone can develop the application they want, and the already developed useful application can be used very easily.
Recent research conducted in Korea, Kim (2014) presented the replaceability of expensive air surveying system through experiments with a post-processing after obtaining the latest image date of the small region using the drone. In a study of Yoon and Lee (2014), they presented the potential for integrated operation by analyzing technical $\cdot$ law $\cdot$ institutional regulations and trends on building geospatial data using drone for the integrated operation to build geospatial data using unmanned aircraft (drone) for the purpose of complementing the drawbacks of conventional aerial photogrammetry. Cho et al. (2014) compared and analyzed the differences between the costs of different processes for producing ortho-image and the production costs of general aerial photogrammetry ortho-image through the UAV aerial photogrammetry in different resolutions and shooting area. Jung et al. (2010) tried developing some techniques and processes that can acquire the three-dimensional geospatial information using low cost drone instead of using expensive air surveying system to have the aerial photos of a small area within urban areas where changes occur frequently. Thus, these photogrammetry using drone are actively conducted in the country. Previously, when we used non-survey camera, the study was very limited, as they did not perform additional camera using the calibration function of the camera itself.

As described above, when we use the smart phone, we can build a very low cost system compared with the existing UAV system, but so far, there is no research on utilizing the smart phone camera technology to the UAV system. Therefore, in this research, the purpose of this paper is to perform a camera calibration on the smart camera, the non-survey camera, as a payload of photogrammetric UAV system, and eventually to evaluate the utilization possibilities for the future by comparing it numerically after generating an ortho-image of the black presence.

\footnotetext{
* Corresponding author: cuchoi@pknu.ac.kr
} 


\section{METHOD OF STUDY}

\subsection{Photogrammetric UAV}

The UAV used in this study is a Double motor Quadcopter type, as it has pixhawk autopilot, 3Dr U-Blox GPS with Compass, a ground-based control and automatic flight are possible. The total weight of UAV is $2.56 \mathrm{~kg}$ and the loading weight is $0.8 \mathrm{~kg}$. The rotary wing UAV generates much more vibration than fixed-wing UAV. For such a vibration in the photogrammetry causes Jello effect of the image. Therefore, this study was designed to install a user created anti-vibration device in order to reduce the vibration transmitted from the Motor rotation.

For the UAV mounted cameras, they use Android-based smart camera of SAMSUNG Galaxy NX. An NX Cameras is embedded with a MEMS sensor, the A-GPS, Accelemter, Gyro sensor to obtain the location and detailed information, and it is possible to perform sending and receiving them, as well as photographic shootings. Though Electric Rotorcraft UAV makes less high-frequency vibration generated in the engine as compared to Gasoline Engine UAV, it is seriously detrimental to the sensor mounted on the UAV even if they generated a very small high-frequency vibration, and also affects the magnetic sensor due to the magnetic field by the motor rotation. Therefore, as fig. 1, an anti-vibration gimbal was attached after installation under the Rotorcraft UAV.

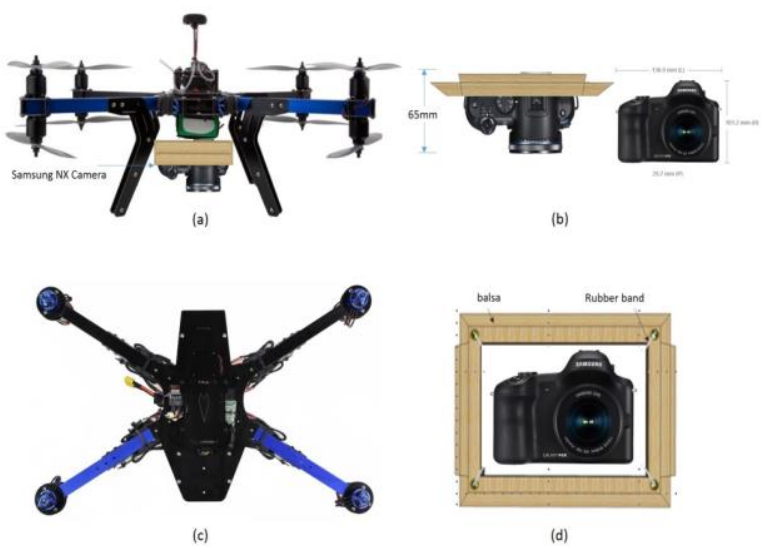

Figure 1. Research UAV \& Vibration Reduction Device

\subsection{Camera Calibration}

Photogrammetry is based on the collinearity condition equation on the basis of the assumption that the point $\boldsymbol{P}$, the projection center $\boldsymbol{O}^{\prime}$, and the point on the focal plane $\boldsymbol{P}^{\prime}$ in the object space form a straight line. However, the actual camera lens can not have the ideal curvature (Fig. 2). For this reason, the ray can not go along with fully straight line to the image plane through the lens, so the calibration on the distortion of the camera lens is essential. And the measurement accuracy of the Photogrammetry system is directly related to the quality of sensor and accurate modeling of interior orientation. Therefore, the camera calibration is an integral part in the photogrammetry system.

The distortion of the camera lens degrades the location accuracy of the image plane. The distortion of the camera lens consists of a radial distortion, asymmetrical distortion, affinity distortion and non-orthogonality deformations. The size of affinity distortion and non-orthogonality deformations is very small, so in these days the distortion of the lens considers only radial distortion and asymmetrical distortion. Equation (1) shows the radial distortion and asymmetric distortion. Radial distortion is symmetric with respect to the principal point of the image, and the amount of calibration of distorted reflections is calculated by the high-order polynomial on the radial distance (Wolf and Dewitt, 2000).

$$
\begin{aligned}
& \text { Equation (1) } \\
& d x^{\prime}=\vec{x}\left(A_{1} r^{2}+A_{2} r^{4}+A_{3} r^{6}\right)+B_{1}\left(r^{2}+2 \vec{x}^{2}\right)+2 B_{2} \vec{x} \vec{y} \\
& d y^{\prime}=\vec{y}\left(A_{1} r^{2}+A_{2} r^{4}+A_{3} r^{6}\right)+2 B_{1} \vec{x} \vec{y}+B_{2}\left(r^{2}+2 \vec{y}^{2}\right)
\end{aligned}
$$

and,

$$
\begin{array}{ll}
A_{1}, A_{2}, A_{3}, & \text { Radial distortion factors } \\
B_{1}, B_{2} & \text { Asymmetrical distortion factors } \\
r & \text { Radial distance }\left(\sqrt{\overline{x^{\prime 2}+\bar{y}^{\prime}}}\right)
\end{array}
$$

For the calculation of Camera calibration and interior orientation parameter (IO parameter), a Multi Target Sheet Calibration that uses several output sheets of Ringed Automatically Detected (RAD) coded targets was performed using the PhotoModeler of EOS system Inc. RAD coded target determines the internal diameter by considering Camera Focal Length, CCD size \& resolution, and in this study, 16 Multi sheets with RAD Target diameter of $12.6 \mathrm{~mm}$ were arranged making the length of $1.8 \mathrm{~m}$ Height and width as Fig. 2, and totally acquired 16 sheets of images respectively twice horizontally and vertically from eight directions

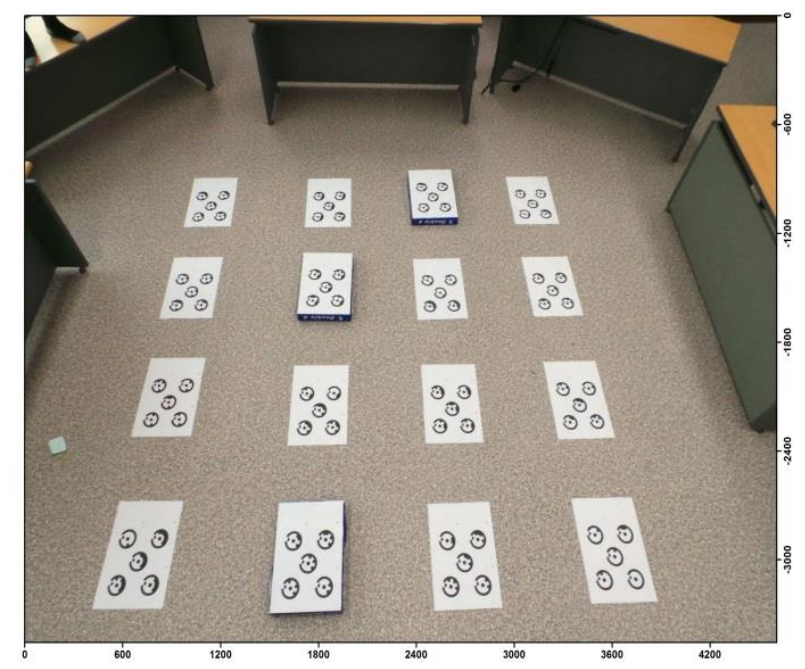

Figure 2. Multi Target Calibration Sheet

\subsection{Field Experiment}

The surrounding area (approximately 40,000 $\mathrm{m}^{2}$ ) of the Institute of Fisheries Sciences, School of Fisheries Sciences in Pukyong National University, which is located in Ilgwangmyeon, Gijang-gun, Busan Metropolitan City, was selected as the place for the Field experiment using the UAV. (Fig. 3). The building of the Institute of Fisheries Sciences and some of the grasslands are scattered in the experiment area. That is, for the experiment area includes the various types of landform relief, the geographical features is suitable for the evaluation of the ortho-image generated by using the image acquired with the help of the developed unmanned aircraft (drone) system. Prior to the actual flight, GCP coordinates antecedent survey for ortho-image evaluation conducted, at that time 13 GCPs 
were determined through the VRS GPS surveying. (Fig. 3). In this study, the aerial signal target was used after being made by the user for the sampling of the feature points and precise accuracy evaluation in the image.

The photogrammetry Using drone was carried out on August 20,2015 . With the shooting altitude of $140 \mathrm{~m}$, the flight speed of $5 \mathrm{~m} / \mathrm{s}$, Forward Overlap $80 \%$, Sidelap $60 \%$, taking a total of 186 photos, carrying out 1 time shooting, and the flight time was approximately 30 minutes. The flying course was constructed using the 'Mission Planner' program, and the flying path is as Fig. 3.
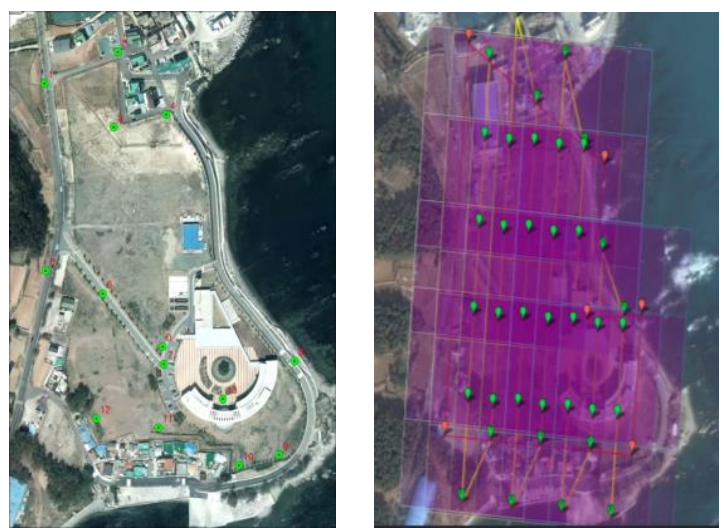

Figure 3. Study area and GCP, Flight Course

\section{RESULT}

\subsection{Camera Calibration}

\begin{tabular}{|c|c|c|c|}
\hline \multirow{4}{*}{ Specification } & \multicolumn{2}{|c|}{ Sensor Size } & $\begin{array}{c}\text { APS-C } \\
(23.5 \times 15.7)\end{array}$ \\
\hline & \multicolumn{2}{|c|}{ Pixel Size } & 4.30 \\
\hline & \multicolumn{2}{|c|}{ Image Format } & $5472 \times 3648$ \\
\hline & \multicolumn{2}{|c|}{ Max. Radius } & 14.13 \\
\hline \multirow{4}{*}{$\begin{array}{c}\text { Calibration } \\
\text { Quality (Pixel) }\end{array}$} & \multicolumn{2}{|c|}{ Adjusted Object RMSE } & 0.075 \\
\hline & \multicolumn{2}{|c|}{ Image Overall RMSE } & 0.575 \\
\hline & \multicolumn{2}{|c|}{ RMSE Residual } & 0.186 \\
\hline & \multicolumn{2}{|c|}{ Max Residual } & 0.817 \\
\hline \multirow{10}{*}{$\begin{array}{l}\text { Intrinsic } \\
\text { parameter }\end{array}$} & \multicolumn{2}{|c|}{ Focal Length (mm) } & 16.806 \\
\hline & \multicolumn{2}{|c|}{ Format Wide (mm) } & 23.990 \\
\hline & \multicolumn{2}{|c|}{ Format Height $(\mathrm{mm})$} & 16.000 \\
\hline & \multicolumn{2}{|c|}{ Max. Radius (mm) } & 14.645 \\
\hline & \multicolumn{2}{|l|}{$\mathrm{Xp}$} & 11.775 \\
\hline & \multicolumn{2}{|l|}{ Yp } & 7.996 \\
\hline & \multirow{2}{*}{ Principal point } & $\mathrm{xH}$ & -0.216 \\
\hline & & $\mathrm{yH}$ & 0.003 \\
\hline & \multicolumn{2}{|c|}{ Pixel Size $X(\mu \mathrm{m})$} & 4.384 \\
\hline & \multicolumn{2}{|c|}{ Pixel Size $Y(\mu \mathrm{m})$} & 4.386 \\
\hline \multirow{4}{*}{$\begin{array}{l}\text { Distortion } \\
\text { Parameter }\end{array}$} & \multirow{2}{*}{$\begin{array}{l}\text { Symmetric } \\
\text { radial }\end{array}$} & $\mathrm{K} 1$ & $5.238 \mathrm{e}-5$ \\
\hline & & $\mathrm{K} 2$ & $-2.684 \mathrm{e}-7$ \\
\hline & \multirow{2}{*}{ Decentering } & $\mathrm{P} 1$ & $1.125 \mathrm{e}-4$ \\
\hline & & $\mathrm{P} 2$ & $-1.552 \mathrm{e}-5$ \\
\hline
\end{tabular}

Table 1. Interior Orientation Parameter by calibration

Calibration methods of camera lens include DLT technique, Tasi technique and an analytical Self-Calibration technique included in the traditional photogrammetry solutions. There are various formulated geometric camera models commonly used for photogrammetry, but the sensor orientation and calibration are mainly carried out by Bundle Adjustment. (Brown, 1971). Bundle Adjustment enables the simultaneous determination of all the system coefficients with accuracy and reliability evaluation of the sampled coefficient. The interior orientation parameters of the camera used in this study were calculated by Photomodeler (Table 1). The bundle adjustment results for the self-calibration and the RMS error of the object coordinate showed both within 0.075 pixel on the target plane in $\mathrm{X}, \mathrm{Y}, \mathrm{Z}$ direction. For photomodeler using the unbalance mode, the distortion on non-orthogonality of the image-axis is not considered generally as the amount is extremely minute, and the section after K2 among the Symmetric radial distortion coefficients tends to not be considered in the distortion correction, because its amount is not large (Fraser, 1997). Fig. 4 shows the Radial distance curve of different smartphone cameras according to the radial distance $r$.

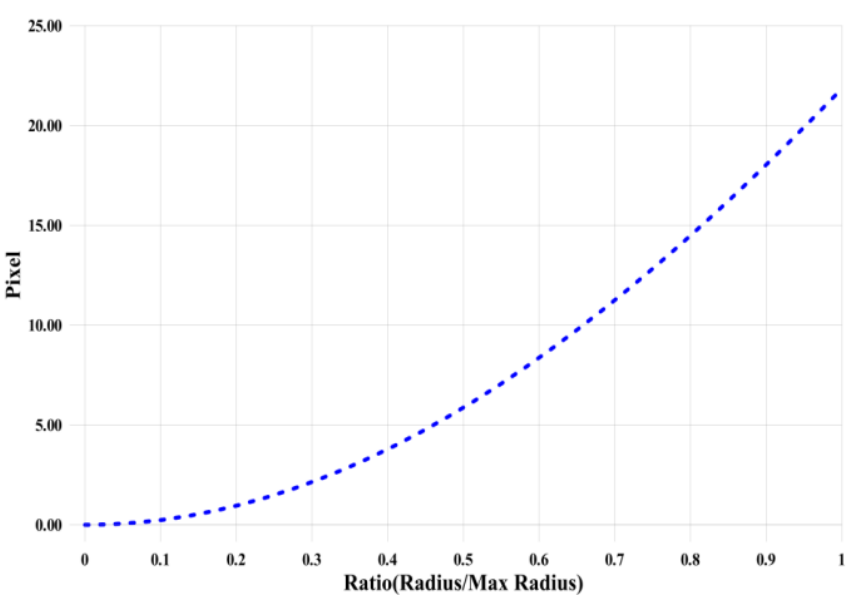

Figure 4. Radial lens distortion curve

\subsection{DSM Extraction \& Ortho Image Generation}
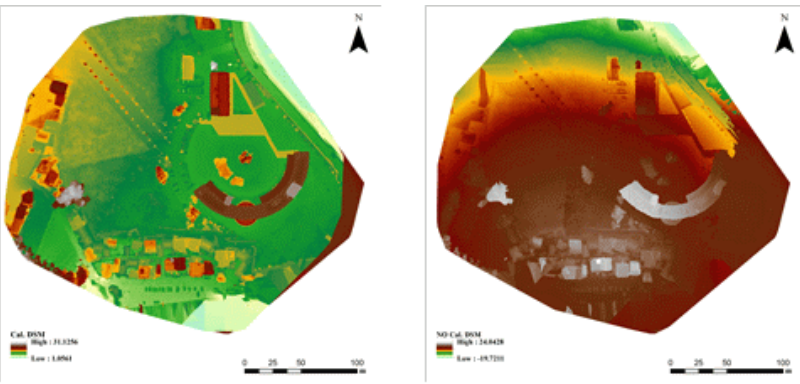

Figure 5. DSM (a) calibrated interior orientation (b) noncalibrated orientation

It generated image-based DEM generated by automatic terrain extraction using aerial triangulation survey from the image obtained from the smart camera. 41 photos were used among a total of 186 photos taken during the flight, two types of DEM were generated according to the presence or absence of a camera calibration coefficient values through 'Pix4D' program (Fig. 5). 
While the range of altitudes showed $-19.7211 \sim 24.0428(\mathrm{~m})$ in DEM that does not apply Camera IO Parameter, the altitude in the image that had inputted IO Parameter was 1.0561 $31.1256(\mathrm{~m})$ showing a significant difference in the minimum value.

According to the DEM data obtained from the study, the minimum value of height in DEM that did not apply the IO Parameter incorrectly showed a negative value. However, it is necessary to have a comparative study through the terrestrial LIDAR Survey, in order to verify the correct altitude values. Based on the resulting digital elevation model (DEM), it generated ortho-image, and the ortho-image generated in accordance with the presence/absence of the interior orientation parameter upon the camera calibration as shown in Fig.6.
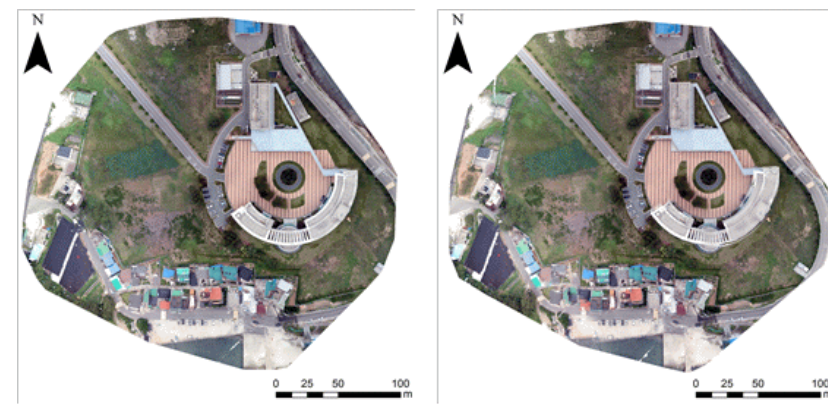

Figure 6. Orthoimage (a)calibrated interior orientation (b)noncalibrated orientation

\subsection{Ortho Image Assesment}

This study applied the Aerial Photogrammetry Operation Regulation (National Geographic Information Institute Notification No. 2013-2236) as the standard in order to evaluate the accuracy of the ortho-image. After calculating the Root Mean Square (RMS) value of the ortho-image, when the camera IO Parameter was not applied, the RMS value showed to $1.971 \mathrm{~m}$, and when the camera IO Parameter was applied, the RMS value showed to $0.022 \mathrm{~m}$ relatively low. It was lower. In this study, as the ortho-image was generated with a $5 \mathrm{~cm}$ of ground resolution taken from an altitude of about $150 \mathrm{~m}$, it is proved to meet the Aerial Photogrammetry Operation Regulation according to the input or no input of camera IO Parameter, as the RMS standard of research area is $0.20 \mathrm{~m}$ made with 1:7000 scales within the above-mentioned accuracy limit. Based on the generated ortho-image, this study analyzed location error of ortho-image with respect to the eight ground control points (GCP) selected as Signal Target areas for research area, and the results have been calculated as Table 2, Table 3.

\begin{tabular}{|c|c|c|c|c|}
\hline $\begin{array}{c}\text { GCP } \\
\text { Name }\end{array}$ & $\begin{array}{c}\text { Error X } \\
{[\mathrm{m}]}\end{array}$ & $\begin{array}{c}\text { Error Y } \\
{[\mathrm{m}]}\end{array}$ & $\begin{array}{c}\text { Error Z } \\
{[\mathrm{m}]}\end{array}$ & $\begin{array}{c}\text { Projection } \\
\text { Error }\end{array}$ \\
\hline 6 & 1.058 & 0.273 & 13.975 & 7.956 \\
\hline 7 & 0.050 & -0.021 & 0.024 & 3.359 \\
\hline 8 & 1.110 & -0.094 & 1.998 & 91.850 \\
\hline 9 & 0.035 & -0.070 & -0.255 & 1.498 \\
\hline 10 & 0.024 & -0.063 & 0.106 & 1.927 \\
\hline 11 & 0.383 & 0.085 & -3.711 & 3.678 \\
\hline
\end{tabular}

\begin{tabular}{|c|c|c|c|c|}
\hline 12 & -0.048 & -1.108 & -2.102 & 3.324 \\
\hline 13 & -0.083 & 0.040 & -0.056 & 4.181 \\
\hline $\begin{array}{c}\text { Mean } \\
{[\mathrm{m}]}\end{array}$ & 0.316218 & -0.119711 & 1.247433 & \\
\hline $\begin{array}{c}\text { RMS } \\
\text { Error } \\
{[\mathrm{m}]}\end{array}$ & 0.560366 & 0.407503 & 5.215058 & \\
\hline
\end{tabular}

Table 2. Ortho image Accuracy using GCP (No Calibration)

\begin{tabular}{|c|c|c|c|c|}
\hline GCP ID & $\begin{array}{c}\text { Error X } \\
{[\mathrm{m}]}\end{array}$ & $\begin{array}{c}\text { Error Y } \\
{[\mathrm{m}]}\end{array}$ & $\begin{array}{c}\text { Error Z } \\
{[\mathrm{m}]}\end{array}$ & $\begin{array}{c}\text { Projection } \\
\text { Error }\end{array}$ \\
\hline 6 & -0.014 & 0.013 & -0.040 & 0.491 \\
\hline 7 & -0.014 & 0.015 & 0.039 & 0.486 \\
\hline 8 & 0.015 & 0.010 & -0.012 & 0.616 \\
\hline 9 & -0.014 & 0.014 & 0.034 & 0.390 \\
\hline 10 & -0.010 & 0.026 & 0.036 & 0.528 \\
\hline 11 & 0.013 & 0.034 & 0.108 & 0.441 \\
\hline 12 & 0.011 & 0.017 & 0.049 & 0.273 \\
\hline 13 & -0.005 & -0.015 & -0.004 & 0.769 \\
\hline $\begin{array}{c}\text { Mean } \\
{[\mathrm{m}]}\end{array}$ & -0.002214 & 0.014098 & 0.026271 & \\
\hline $\begin{array}{c}\text { RMS } \\
\text { Error } \\
{[\mathrm{m}]}\end{array}$ & 0.012322 & 0.019256 & 0.049773 & \\
\hline
\end{tabular}

Table 3. Ortho image Accuracy using GCP (Calibration)

As the result of measuring the distance between the pixels between each of Ortho Images with respect to the eight ground control points (GCP), when the IO Parameter was not applied, the differences between the points on the image and the ground control points (GCP) showed respectively $0.31 \mathrm{~m}, 0.11 \mathrm{~m}$ and $1.24 \mathrm{~m}$ by $\mathrm{X}, \mathrm{Y}, \mathrm{Z}$ direction, and when the IP Parameter was applied, the differences showed respectively $-0.002 \mathrm{~m}, 0.014 \mathrm{~m}$ and $0.026 \mathrm{~m}$ by $\mathrm{X}, \mathrm{Y}, \mathrm{Z}$ direction. For the RMS on the image, when the IP Parameter was not applied, $\mathrm{X}$ was $0.560 \mathrm{~m}, \mathrm{Y}$ was $0.407 \mathrm{~m}$, and $\mathrm{Z}$ was $5.215 \mathrm{~m}$, and when the IP Parameter was applied $\mathrm{X}$ was $0.012 \mathrm{~m}, \mathrm{Y}$ was $0.019 \mathrm{~m}$, and $\mathrm{Z}$ was $0.049 \mathrm{~m}$. Comparing with the RMS when considering the IO parameters following the camera calibration and the one without consideration, the horizontal error shows about 2 times, and the vertical error shows about 10 times better result.

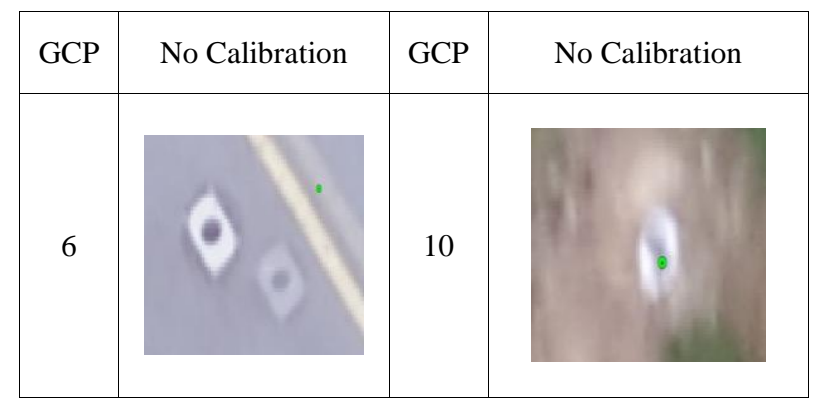




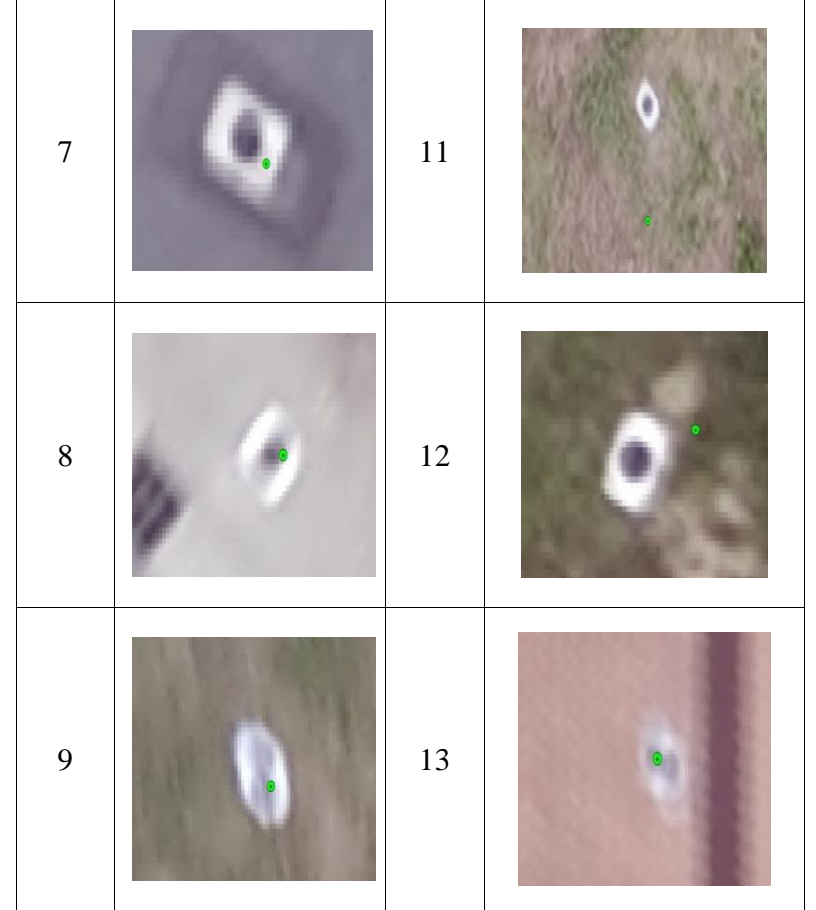

Figure 7. Absence of IO Parameter

Fig. 7 compared the images of 8 different ground control points (GCP) after having the ortho-image results generated according to the presence and absence of the camera calibration. For the image that does not apply the IO parameter, also the images are not overlapped exactly as the visions are not overlapped well at No. 6 GCP in the process of making ortho-image, and the GCP is also out of the Signal Target. Though the GCP is close within the Signal Target at No. 7 GCP, it was still out of it, and the GCP shows within the Signal Target at No. 8, 9, 10, but it is not located exactly in the center of Target. It shows that the distance between the GCP and Singal Target is quite apart from each other at No. 11 and 12, and the Signal Target image on the vision is not clear, as it is determined that the images are not overlapped properly during the ortho-image generation process at No. 13. In contrast, it can be seen that all of the eight GCPs are close to the center of Signal Target in the ortho-images applied to the IO Parameter.

\section{CONCLUSION}

This study evaluated the utilization possibilities of a non-survey camera as a payload by analyzing the accuracy of ortho-image depending on the presence and absence of camera calibration after producing a digital elevation model and ortho-image using a drone equipped with a non-survey smart camera. At first, it carried out camera calibration using PhotoModeler for the photos obtained by the Coded Target, and applied camera IO Parameter to the study after acquiring it. It generated the ortho-image and DEM of the research area due to the presence and absence of the IO parameter using the images through the flight, and for the DEM that was not applied to the IO Parameter, the minimum value was somewhat inaccurate.

For the RMS representing the accuracy during the aerial triangulation, it showed $0.022 \mathrm{~m}$ with considering the IO parameter, but without the RMS was about $1.971 \mathrm{~m}$ without considering the IO parameter showing a large deviation. As the result of the accuracy evaluation of the DEM and ortho-image generated finally, the RMS value is 89 times lower depending on the IO Parameter consideration. Thereby, in the case of utilizing the UAV mounted non-survey camera, it can acquire ortho-images of high accuracy and use them in a variety of practical research when applying the camera calibration coefficient values.

Considering that the above results are the ones presented by only one smart camera, smart phones can be used sufficiently as a payload for UAV system, also they are expected to be able to responsible enough to direct or indirect functions by being mounted on the existing UAV system.

\section{ACKNOWLEDGEMENTS}

This work was supported by the BK21 Plus project of The Research management team of Earth Environmental Hazard System at Pukyong National University

\section{REFERENCES}

Brown, D.C., 1971. Close-range camera calibration, PE \& RS, 37(8): 855-866.

Chang, Y.F., C.S. Chen, and H. Zhou, 2009. Smart phone for mobile commerce, Computer Standards \& Interfaces, 31: 740747.

Chiabrando, F., F. Nex, D. Piatti, and F. Rinaudo, 2011. UAV and PRV systems for photogrammetric surveys in archaelogical areas: two tests in the Piedmont region (Italy), Journal of Archaeological Science, 38: 697-710.

Cho, J.H., J.M. Kim, Y.S. Choi, and I.H. Jeong, 2014 Accuracy Study of Orthoimage Map Production using UAV. Proc. of 2014 Korean Society of Civil Engineers Annual Conference, pp. 1739-1740 (in Korean with English abstract).

Dalamagkidis K., K.P. Valavanis, and L.A. Piegl, 2008. On unmanned aircraft systems issues, challenges and operational restrictions preventing integration into the National Airspace System, Progress Aerospace Sciences, 44: 503-519.

Eisenbeiss, H., and L. Zhang, 2006. Comparison of DSMs generated from mini UAV imagery and terrestrial laser scanner in a cultural heritage application. International Archives of Photogrammetry Remote Sensing and Spatial Information Sciences, 36(5): 90-96.

Fraser, 1997. Digital camera self-calibration. ISPRS Journal of Photogrammetry and Remote Sensing, 52(4): 149-159.

Jung, S.H., H.M. Lim, and J.G. Lee, 2010. Acquisition of 3D Spatial Information using UAV Photogrammetric Method, Journal of the Korean Society of Surveying, Geodesy, Photogrammetry and Cartography, 28(1):161-167.

Kim, S.K., Y.D. Sung, and K.W. Kim, 2014. A study on methods of utilizing unmanned aerial vehicle(UVA) in the area of spaial information, Korean Association of Cadastre Information, 28(1): 169-178 (in Korean with English abstract)

Wolf, P.R., and B.A. Dewitt, 2000. Elements of Photogrammetry with Applications in GIS. McGraw-Hill, 
Boston, Massachusetts.

Yoon, B.Y. and J.W. Lee, 2014. A Study on Application of the UAV in Korea for Integrated Operation with Spatial Information, Journal of Korean Society for Geospatial Information System, 22(2):3-9 (in Korean with English abstract). 